\title{
COVID-19 Health Precautions: Examining Demographic and Socioeconomic Disparities
}

Anthony Jehn, ${ }^{1}$ University of Western Ontario

Anna Zajacova, University of Western Ontario

Manuscript word count: 2,591

Word count including abstract, text, tables, and figures: 3,918

Tables: 3

Figures: 2

Supplemental Tables: 2

\section{Acknowledgements:}

This study was supported by funding from a Mitacs Research Training Award.

${ }^{1}$ Corresponding author's mailing address: Social Science Centre, Room 5225C, London, Ontario, Canada, N6H 0J9. Email: ajehn2@uwo.ca. 


\begin{abstract}
The COVID-19 pandemic has required the adoption of new precautionary health behaviours to reduce the risk of infection. This study examines adherence to four key precautionary behaviours among Canadian adults: wearing face masks, increasing the frequency of hand washing, practicing social distancing, and avoiding large crowds. Data are drawn from the Canadian Perspective Survey Series 3: Resuming Economic and Social Activities During COVID-19, administered by Statistics Canada in June 2020. Weighted descriptives calculate overall adherence levels and logistic regressions models of each behaviour as a function of demographics and socioeconomic status identify vulnerable segments of the population. We find a nearly universal increase in hand washing (94\%) and high adherence to social distancing and avoiding crowds ( $82 \%$ and $84 \%$ respectively). Adherence to the use of face masks is much lower (67\% on average); moreover, there are significant disparities in their use. Women, older adults, immigrants, and urban residents are much more likely to adhere to mask wearing, and other precautionary behaviours, than men, younger adults, Canadian-born, and rural residents. Canadian adults with a university degree are also the most likely to wear face masks and avoid large crowds. The most significant disparities in the use of COVID-19 precautions are found across demographic characteristics. These estimates have substantial implications for policy and potential public health interventions.
\end{abstract}

\title{
KEYWORDS
}

COVID-19, Precautions, Health, Disparities, Canada, Adults 


\section{INTRODUCTION:}

The COVID-19 pandemic has required Canadians to adopt new precautionary health behaviours. The virus is highly transmittable, with moderate to severe illness reported in approximately $20 \%$ of all cases (Kucharski et al. 2020; Riou and Althaus 2020). According to the World Health Organization (WHO 2020), wearing face masks, increasing the frequency of hand washing, practicing social distancing, and avoiding large crowds are the primary means of reducing the risk of infection. These behaviours represent the most important actions that Canadians can take to help fight the pandemic. As a result, research is required to understand rates of adherence to these precautions in the Canadian population, as well as disparities in adherence, in order to assess potential vulnerabilities across various segments of the population.

While hand hygiene and social distancing are important behaviours, wearing a face mask is particularly vital as it significantly reduces transmission of the virus (Brankston et al. 2020). Wearing a mask is predominately seen as a behaviour aimed at protecting others, rather than our own self-interests (Adeel et al. 2020; van der Linden and Savoie 2020). In fact, a recent online poll found that the majority of Canadian respondents (87\%) believed wearing a mask to be a civic duty as it protects others from the risk of infection (Berthiaume 2020). However, maskwearing in countries around the world ranges from 1\% in Denmark and Finland to over $90 \%$ in Singapore and the Philippines, as adherence is greatly influenced by government regulations (CFR 2020). Canadian mask usage has gradually increased from $10 \%$ at the start of the pandemic in March 2020 to approximately 63\% in late May (Mohammed, Johnston, and van der Linden 2020). The gradual change reflects shifts in the importance attributed to mask usage by public health officials. Moreover, compliance has also been found to increase as a result of more aggressive public health policy initiatives (Armstrong, Lebo, and Lucas 2020). 
It is also critical to assess differences among population groups in adherence to precautionary behaviours. During the SARS outbreak in the UK, Bish and Michie (2010) found being older, female, more educated, and non-White to be associated with a higher likelihood of adopting precautionary behaviours such as hand washing, wearing face masks, and avoiding crowds. The use of precautions during the COVID-19 pandemic has also been found to vary across population subgroups. For example, some recent evidence from Canada suggests women and older adults are more likely than men and younger adults to follow government recommended health behaviours during the pandemic (Brankston et al. 2020; Clark et al. 2020). A recent study also found that immigrant, urban residence, single dwelling home, and higher educated Canadians are more likely to practise social distancing, compared to non-immigrant, rural residence, and less educated Canadians (Chan 2020). Moreover, respondents living in more urban areas also report higher levels of mask use, compared to rural areas where mask use is particularly low (Brankston et al. 2020). While these recent studies are not nationally representative, the findings support the need to conduct a comprehensive analysis on the use of precautions both in aggregate and across demographics and measures of socioeconomic status.

The present study uses recently released data on behaviours during the COVID-19 pandemic to assess the use of health precautions. We provide national estimates on the prevalence of precautionary behaviours across the Canadian adult population. We also assess differences by demographics and socioeconomic status in order to identify vulnerable segments of the population that may require public health intervention. Demographic characteristics and measures of socioeconomic status reflect structural positions and influences that define our exposure to various health-related norms and customs, which in turn shapes our health-related behaviours (Burdette et al. 2017; Mollborn et al. 2014; Ross, Hill, and Mirowsky 2016). 


\section{METHODS}

\section{Data:}

The data for our analyses are from the Canadian Perspective Survey Series 3: Resuming Economic and Social Activities During COVID-19 (CPSS-3), administered by Statistics Canada. The purpose of the survey was to collect information about a wide range of social and economic conditions as Canada continued to navigate the pandemic restrictions. Data were collected between June $15^{\text {th }}$ and June $21^{\text {st }}, 2020$. The sampling frame includes Canadians aged 15 and older across the ten provinces; the institutionalized population and residents of the Yukon, Northwest Territories, and Nunavut are excluded from the sample frame. The data were collected using short online surveys with a sample size of 4,209 respondents.

We define the target population as Canadian adults aged 25 and over. We exclude 203 respondents (4.8\% of total) age $15-24$ because this age category comprises adolescents and young adults with incomplete measures of socioeconomic status, such as educational attainment and employment. We further exclude 67 respondents (1.6\% of total) with missing responses on their use of COVID-19 precautions or employment status. The final analytic sample size includes 3,939 respondents.

\section{Measures:}

\section{$\underline{\text { Outcomes }}$}

The data include information about four precautionary behaviours including wearing face masks, washing hands "more frequently," practising social distancing, and avoiding large crowds. These behaviours were assessed with the question "Which of the following precautions will you take or continue to take as the COVID-19 safety measures are relaxed?" with respondents being able to answer "yes" or "no" for each behaviour. 


\section{Covariates}

Demographic characteristics include gender (male as reference), age groups (originally coded in 10-year groups from 25-34 to 75+; included in all models as a categorical variable: 25 to 44 as reference, 45 to 64, and 65+), immigrant status (Canadian-born as reference versus foreignborn), urban as reference versus rural residence, marital status (married/common-law as reference, previously married, and single), and the presence of children (no children under 18 at home as reference versus at least one child at home). Socioeconomic status was captured using level of education (high school or less as reference, trades certificate, college diploma, and university degree), dwelling type (single detached as reference, low-rise apartment, high-rise apartment, and other), and employment status coded with employed as reference, absent from work, and not employed. The 'absent' category distinguished whether the absence was COVIDrelated or not; we combined the two categories because the two groups were small and did not significantly differ.

\section{Statistical Analysis:}

We first describe the distribution of all variables in the target population (Table 1). We then estimate a series of bivariate logistic regression models for each precaution and each covariate to identify gross intergroup differences (Table 2). To better interpret the results from these models, we calculate average adjusted probabilities from the estimated odds ratios and present the findings graphically for the demographic characteristics (Figure 1a) and by socioeconomic status (Figure 1b). Finally, we estimate fully adjusted logistic regression models for each precaution, which include all controls. The analyses are all weighted to adjust for the complex sampling design of the CPSS. 


\section{RESULTS}

Table 1 provides weighted descriptive statistics for all variables in this study. The results indicate substantial variability in the use of recommended COVID-19 precautions among Canadian adults. Washing hands more frequently has the highest rate of adherence (94\%), followed by avoiding crowds (84\%) and social distancing (82\%). Wearing face masks has the lowest rate of adherence, with only approximately $67 \%$ of the population reporting the use of face masks. These differences have important policy implications, particularly as these behaviors remain the most prominent means of slowing the spread of the virus across the country.

[insert Table 1 here]

Table 2 provides bivariate logistic regression results which is estimated separately for each precaution and population group, with odds ratios shown. The estimates indicate gender, age group, immigrant status, urban versus rural residence, level of education, and employment status have the most prominent interpopulation group disparities. To provide an easy-to-interpret output, we convert the estimates into predicted probabilities of adopting COVID-19 precautions for each of those groups. The probabilities are plotted in Figures 1a \& 1b, along with corresponding $95 \%$ confidence intervals.

[insert Table 2 here]

Figure 1a displays bivariate predicted probabilities for gender, age group, immigrant status, and urban versus rural residence. The results indicate significant intergroup disparities in the use of precautions, particularly in the use of face masks. Female, older, immigrant, and urban residence adults are the most likely to wear face masks, compared to male, younger, non-immigrant, and rural residence adults. Probabilities of practicing social distancing and avoiding large crowds follows a similar pattern, with the exception of adults living in either urban or rural areas where 
the use of these precautions do not significantly differ. Increased hand washing has the least variation in probabilities within population groups; however, female and older adults are still more likely to have increased their hand washing, compared to male and younger adults.

[insert Figure 1a here]

Figure $1 \mathrm{~b}$ includes predicted probabilities for level of education and employment status. Canadian adults with a trades certificate and those currently employed are the least likely to wear face masks, compared to adults with a university degree and those who are either absent from work or not employed. Adults with a trades certificate are also the least likely to practice social distancing, avoid large crowds, and wash their hands more frequently. Collectively, these findings indicate that the Canadian adult population with a trades certificate consistently have the lowest probabilities of adopting any of the COVID-19 precautions which represents an important population group for public health interventions.

[insert Figure $1 b$ here]

Table 3 presents fully adjusted logistic regression models estimating the use of each precaution, with odds ratios shown. The models include all covariates in order to examine how these measures effect the bivariate intergroup differences. The results indicate that the use of face masks continues to have the greatest disparities across the adult population. In contrast, differences in frequency of hand washing, practising social distancing, and avoiding large crowds are attenuated after controlling for demographic and socioeconomic characteristics. However, large disparities continue to be found for gender where women are between approximately 50\% (social distancing and avoiding crowds) and 150\% (hand washing) more likely to use COVID-19 precautions, compared to men. Adults over the age of 65 are also 
between approximately $110 \%$ (hand washing) and 135\% (avoiding crowds) more likely to use COVID-19 precautions, compared to younger adults.

[insert Table 3 here]

\section{DISCUSSION}

COVID-19 health precautions remain a critical component for reducing the risk of infection and slowing the spread of the pandemic. Government health officials continue to recommend wearing face masks, increasing the frequency of hand washing, practicing social distancing, and avoiding large crowds (Government of Canada 2020). We examined adherence to these precautions, and disparities by demographics and measures of socioeconomic status, in order to identify vulnerable segments of the Canadian adult population. These estimates have substantial implications for policy and potential public health interventions.

The overall adherence among Canadian adults differed across the four precautionary behaviours. Almost all Canadians (94\%) report washing their hands more frequently, $84 \%$ avoid large crowds, and $82 \%$ report social distancing. In contrast, only $67 \%$ of the adult population report that they "Wear a mask in public places where physical distancing is difficult." The nearly universal compliance with increased hand washing may be overreported. Borchgrevink, Cha, and Kim (2013) found people typically do not wash their hands as frequently as they report. The survey question is also non-specific, as it does not clarify whether the increase was overall or only after certain activities and captures not so much the level of hand washing but increase since, presumably, before COVID-19.

Avoiding large crowds (84\%) and social distancing (82\%) also have relatively high rates of adherence. As these are fairly similar behaviours, comparable rates of adherence to these behaviours is expected. Wearing face masks has the lowest rate of adherence as only 
approximately $67 \%$ of the adult population report wearing a mask. The proportion is similar to a recent Canadian study that found $63 \%$ of respondents reported wearing masks during in late May 2020 (Mohammed, Johnston, and van der Linden 2020), but well below the proportions in Singapore or the Philippines, where over 90\% of adults wear a mask (CFR 2020). The low use of face masks is especially problematic given how critical it is for reducing transmission of the virus (Brankston et al. 2020) and for lowering mortality rates (WHO 2020).

We also found that the precautionary behaviors differed across population groups. With respect to mask wearing, female, older, immigrant, and urban residents are more likely to wear face masks compared to male, younger, non-immigrant, and rural residents. The observed pattern of intergroup disparities is similar to other studies examining health behaviours in general (Cutler and Lleras-Muney 2010; Baron et al. 2015). Based on these findings, the average prevalence of mask wearing would be approximately $81 \%$ if all Canadians wore masks at the rate of the highest compliers, compared to the actual $67 \%$. Similar patterns of disparities are also found for practising social distancing and avoiding large crowds. Increased hand washing is much more consistent across all population groups; however, female and older adults are still significantly more likely to have increased their hand washing, compared to male and younger adults. Measures of socioeconomic status are also significant predictors of adherence to precautionary behaviours. Canadian adults with a trades certificate are the least likely to adhere to all four precautionary behaviors - in fact, they are only half as likely to wear masks, wash hands, engage in social distancing, and avoiding crowds, compared to adults with a high school degree or less. In contrast, adults with a university degree are most likely to wear a mask and avoid large crowds. Significant disparities in the use of masks was also found among those employed, compared to those who are either absent from work or not employed. This is consistent with a 
recent study that found adults with lower levels of education to be significantly more likely to engage in negative health behaviours, such as smoking, during the COVID-19 pandemic (Zajacova et al. 2020). Across our measures of socioeconomic status, increased hand washing is again much more consistent within population groups, except adults with a trades certificate are still the least likely to wash their hands more frequently.

We also controlled for differences in both demographics and socioeconomic status for the Canadian adult population in aggregate. Disparities in the use of precautions across demographic characteristics remains consistent, while the pattern across measures of socioeconomic status is attenuated. This is particularly evident across levels of education, which suggests differences in demographic characteristics explain a significant proportion of intergroup disparities. Although, adults with a university degree are still found to be more likely to wear face masks and avoid large crowds, compared to less educated adults.

There are a few limitations to our findings. The data comes from a cross-sectional survey which does not allow us to examine how the use of precautions may have evolved over time. The data is also missing critical demographic characteristics (e.g., race and province) as well as measures of socioeconomic status (e.g., income and occupation). The availability of these measures in future waves of the data is encouraged.

\section{CONCLUSION}

Relatively high rates of adoption are found for most of the precautionary behaviours, particularly for increasing the frequency of hand washing. However, significant improvements need to be made in the use of face masks. As previously discussed, the average adoption rate would be approximately $81 \%$ if all Canadians wore masks at the rate of the highest compliers. In order to reach that rate of adoption, policymakers should target vulnerable segments of the population 
including male, younger, non-immigrant, and rural residence adults. Potential public health interventions should also account for the possible overreporting in the adoption of COVID-19 health precautions. 


\section{REFERENCES}

Adeel, Abdul Basit, Michael Catalano, Olivia Catalano, Grant Gibson, Ezgi Muftuoglu, Tara Riggs, Mehmet Halit Sezgin, Olga Shvetsova, Naveed Tahir, and Julie VanDusky-Allen. 2020. "COVID-19 Policy Response and the Rise of the Sub-National Governments." Canadian Public Policy, Accepted-version.

Armstrong, David A, Matthew J Lebo, and Jack Lucas. 2020. "Do COVID-19 Policies Affect Mobility Behaviour? Evidence from 75 Canadian and American Cities." Canadian Public Policy 46 (S2): S127-44.

Baron, Ruth, Judith Manniën, Saskia J te Velde, Trudy Klomp, Eileen K Hutton, and Johannes Brug. 2015. "Socio-Demographic Inequalities across a Range of Health Status Indicators and Health Behaviours among Pregnant Women in Prenatal Primary Care: A CrossSectional Study." BMC Pregnancy and Childbirth 15 (1): 261.

Berthiaume, Lee. 2020. "Majority of Canadians Say Wearing a Mask during Coronavirus Pandemic Is a Civic Duty: Poll." Global News, 2020. https://globalnews.ca/news/7350128/canadians-support-wearing-mask-coronavirus/.

Bish, Alison, and Susan Michie. 2010. "Demographic and Attitudinal Determinants of Protective Behaviours during a Pandemic: A Review." British Journal of Health Psychology 15 (4): 797-824.

Borchgrevink, Carl P, JaeMin Cha, and SeungHyun Kim. 2013. "Hand Washing Practices in a College Town Environment." Journal of Environmental Health 75 (8): 18-25.

Brankston, Gabrielle, Eric Merkley, David N Fisman, Ashleigh R Tuite, Zvonimir Poljak, Peter J Loewen, and Amy L Greer. 2020. "Sociodemographic Disparities in Knowledge, Practices, and Ability to Comply with COVID-19 Public Health Measures in Canada." MedRxiv.

Burdette, Amy M, Belinda L Needham, Miles G Taylor, and Terrence D Hill. 2017. "Health Lifestyles in Adolescence and Self-Rated Health into Adulthood." Journal of Health and Social Behavior 58 (4): 520-36.

Clark, Cory, Andrés Davila, Maxime Regis, and Sascha Kraus. 2020. "Predictors of COVID-19 Voluntary Compliance Behaviors: An International Investigation." Global Transitions 2: 76-82.

Council on Foreign Relations (CFR). 2020. "Which Countries Are Requiring Face Masks?" 2020. https://www.cfr.org/in-brief/which-countries-are-requiring-face-masks.

Cutler, David M, and Adriana Lleras-Muney. 2010. "Understanding Differences in Health Behaviors by Education.” Journal of Health Economics 29 (1): 1-28.

Government of Canada. 2020. "Coronavirus Disease (COVID-19): Prevention and Risks." 2020. https://www.canada.ca/en/public-health/services/diseases/2019-novel-coronavirusinfection/prevention-risks.html.

Kucharski, Adam J, Timothy W Russell, Charlie Diamond, Yang Liu, John Edmunds, Sebastian Funk, Rosalind M Eggo, Fiona Sun, Mark Jit, and James D Munday. 2020. "Early Dynamics of Transmission and Control of COVID-19: A Mathematical Modelling Study." The Lancet Infectious Diseases.

Linden, Clifton van der, and Justin Savoie. 2020. "Does Collective Interest or Self-Interest Motivate Mask Usage as a Preventive Measure against COVID-19?" Canadian Journal of Political Science/Revue Canadienne de Science Politique, 1-8.

Mohammed, Anwar, Regan M Johnston, and Clifton van der Linden. 2020. "Public Responses to Policy Reversals: The Case of Mask Usage in Canada during COVID-19." Canadian Public 
Policy 46 (S2): S119-26.

Mollborn, Stefanie, Laurie James-Hawkins, Elizabeth Lawrence, and Paula Fomby. 2014. "Health Lifestyles in Early Childhood." Journal of Health and Social Behavior 55 (4): 386402.

Riou, Julien, and Christian L Althaus. 2020. "Pattern of Early Human-to-Human Transmission of Wuhan 2019 Novel Coronavirus (2019-NCoV), December 2019 to January 2020.” Eurosurveillance 25 (4): 2000058.

Ross, Catherine E, Terrence D Hill, and John Mirowsky. 2016. "Reconceptualizing Health Lifestyles: The Case of Marriage." Research in the Sociology of Health Care 34: 243-60.

Statistics Canada. 2020. "Canadian Perspectives Survey Series 3: Resuming Economic and Social Activities during COVID-19.” 2020. https://www150.statcan.gc.ca/n1/dailyquotidien/200708/dq200708a-eng.htm.

The World Health Organization (WHO). 2020. "Coronavirus Disease (COVID-19) Advice for the Public.” 2020. https://www.who.int/emergencies/diseases/novel-coronavirus2019/advice-for-public.

Zajacova, Anna, Anthony Jehn, Matthew Stackhouse, Patrick Denise, and Howard Ramos. 2020.

"Changes in Health Behaviours during the Covid-19 Pandemic: Sociodemographic Disparities." Canadian Journal of Public Health. 


\begin{tabular}{lc}
\hline \multicolumn{2}{l}{ Table 1: Characteristics of the target population - Canadian Perspective Survey Series 3 } \\
\hline COVID-19 precautions (\%) & \\
\hline Wearing masks & 67.3 \\
Hand washing & 94.3 \\
Social distancing & 82.4 \\
Avoiding crowds & 84.1 \\
\hline Demographics (\%) & \\
\hline Female & 50.9 \\
Age & \\
25 to 44 & 38.5 \\
45 to 64 & 37.5 \\
65+ & 24.0 \\
Immigrant & 24.6 \\
Rural & 15.7 \\
Marital status & \\
Married/Common-law & 70.6 \\
Previously married & 12.8 \\
Single & 16.6 \\
Children present & 28.3 \\
Socioeconomic status (\%) & \\
\hline Level of Education & \\
High school or less & 30.7 \\
Trades certificate & 11.2 \\
College diploma & 22.6 \\
University degree & 35.5 \\
Employment status & \\
Employed & 52.0 \\
Absent from work & 6.3 \\
Not employed & 41.7 \\
Dwelling type & \\
Single detached & 60.9 \\
Low-rise apartment & 12.9 \\
High-rise apartment & 9.5 \\
Other & \\
\hline N = 3939 & \\
\hline Descriptives include sampling weights to account for unequal probability of selection into the sample \\
Source: Canadian Perspective Survey Series 3 \\
\end{tabular}




\begin{tabular}{|c|c|c|c|c|}
\hline & Wearing masks & Hand washing & Social distancing & Avoiding crowds \\
\hline \multicolumn{5}{|l|}{ Demographics } \\
\hline Female & $1.82^{* * * *}$ & $2.63 * * *$ & $1.50^{* *}$ & $1.75^{* * *}$ \\
\hline \multicolumn{5}{|l|}{ Age } \\
\hline 25 to 44 & -- & -- & -- & -- \\
\hline 45 to 64 & $1.35^{*}$ & 0.82 & $1.34 *$ & $1.42 *$ \\
\hline $65+$ & $2.19 * * *$ & 1.71 & $1.52 *$ & $2.86^{* * *}$ \\
\hline Immigrant & $2.68 * * *$ & 1.23 & $1.79 * * *$ & $2.58 * * *$ \\
\hline Rural & $0.53 * * *$ & 1.15 & 0.85 & 0.82 \\
\hline \multicolumn{5}{|l|}{ Marital status } \\
\hline Married/Common-law & -- & -- & -- & -- \\
\hline Previously married & 0.97 & 0.87 & 1.06 & 0.78 \\
\hline Single & $0.58 * *$ & 0.85 & 0.72 & $0.52 * * *$ \\
\hline Children present & 0.83 & 1.20 & 0.83 & 0.79 \\
\hline \multicolumn{5}{|l|}{ Socioeconomic status } \\
\hline \multicolumn{5}{|l|}{ Level of Education } \\
\hline High school or less & -- & -- & -- & -- \\
\hline Trades certificate & $0.51 * *$ & $0.46^{*}$ & $0.58 *$ & $0.47 * *$ \\
\hline College diploma & 0.95 & 0.78 & 1.11 & 0.89 \\
\hline University degree & $1.62 * * *$ & 1.20 & 1.25 & $1.59 *$ \\
\hline \multicolumn{5}{|l|}{ Employment status } \\
\hline Employed & -- & -- & -- & -- \\
\hline Absent from work & $1.56^{*}$ & 1.68 & 1.48 & 1.45 \\
\hline Not employed & $1.66^{* * *}$ & 1.27 & $1.32 *$ & $1.85^{* * *}$ \\
\hline \multicolumn{5}{|l|}{ Dwelling type } \\
\hline Single detached & -- & -- & -- & -- \\
\hline Low-rise apartment & 1.14 & 1.26 & 0.90 & 1.06 \\
\hline High-rise apartment & $1.97 * *$ & 0.96 & $2.07 * *$ & 1.21 \\
\hline Other & 1.08 & 1.16 & 1.01 & 1.03 \\
\hline Observations & 3939 & 3939 & 3939 & 3939 \\
\hline
\end{tabular}

$* \mathrm{p}<0.05 ; * \mathrm{p}<0.01 ; * * \mathrm{p}<0.001$

Each cell shows an odds ratio from a separate bivariate model estimating the association between the predictor and each outcome; that is, each OR is from a separate model. All models include sampling weights to account for unequal probability of selection into the sample.

Source: Canadian Perspective Survey Series 3 


\begin{tabular}{|c|c|c|c|c|}
\hline & Wearing masks & Hand washing & Social distancing & Avoiding crowds \\
\hline \multicolumn{5}{|l|}{ Demographics } \\
\hline Female & $1.77 * * *$ & $2.56 * * *$ & $1.41 *$ & $1.62 * * *$ \\
\hline \multicolumn{5}{|l|}{ Age } \\
\hline 25 to 44 & -- & -- & -- & -- \\
\hline 45 to 64 & $1.36^{*}$ & 0.94 & 1.23 & 1.34 \\
\hline $65+$ & $2.03 * * *$ & $2.12 *$ & 1.26 & $2.35^{* *}$ \\
\hline Immigrant & $2.12 * * *$ & 1.01 & $1.60 * *$ & $2.12 * *$ \\
\hline Rural & $0.61 * * *$ & 1.23 & 0.95 & 0.94 \\
\hline \multicolumn{5}{|l|}{ Marital status } \\
\hline Married/Common-law & -- & -- & -- & -- \\
\hline Previously married & 0.75 & 0.69 & 0.92 & 0.58 \\
\hline Single & $0.69 *$ & 1.07 & 0.81 & $0.64 *$ \\
\hline Children present & 0.90 & 1.33 & 0.83 & 0.86 \\
\hline \multicolumn{5}{|l|}{ Socioeconomic status } \\
\hline \multicolumn{5}{|l|}{ Level of Education } \\
\hline High school or less & -- & -- & -- & -- \\
\hline Trades certificate & 0.68 & 0.61 & 0.69 & 0.65 \\
\hline College diploma & 1.12 & 0.87 & 1.20 & 1.10 \\
\hline University degree & $1.73 * * *$ & 1.38 & 1.27 & $1.85^{* *}$ \\
\hline \multicolumn{5}{|l|}{ Employment status } \\
\hline Employed & -- & -- & -- & -- \\
\hline Absent from work & 1.49 & 1.36 & 1.48 & 1.34 \\
\hline Not employed & $1.33^{*}$ & 0.99 & 1.17 & 1.45 \\
\hline \multicolumn{5}{|l|}{ Dwelling type } \\
\hline Single detached & -- & -- & -- & -- \\
\hline Low-rise apartment & 1.04 & 1.27 & 0.84 & 1.09 \\
\hline High-rise apartment & 1.52 & 0.97 & $1.83^{*}$ & 1.01 \\
\hline Other & 0.93 & 1.12 & 0.94 & 0.95 \\
\hline Observations & 3939 & 3939 & 3939 & 3939 \\
\hline
\end{tabular}

All models include sampling weights to account for unequal probability of selection into the sample Source: Canadian Perspective Survey Series 3 
Figure 1a: Bivariate Predicted Probabilities by Demographics

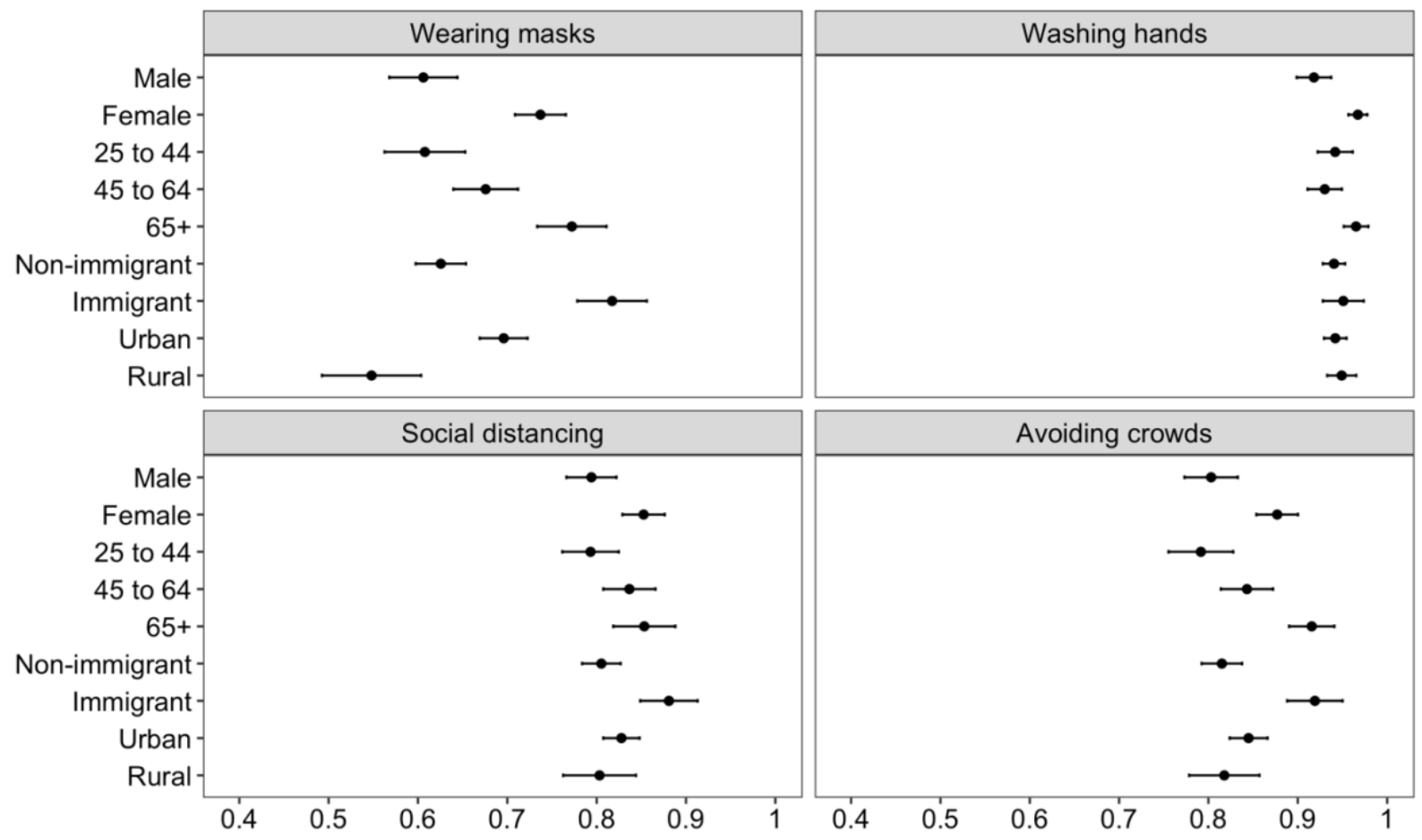

Figure 1b: Bivariate Predicted Probabilities by Socioeconomic Status

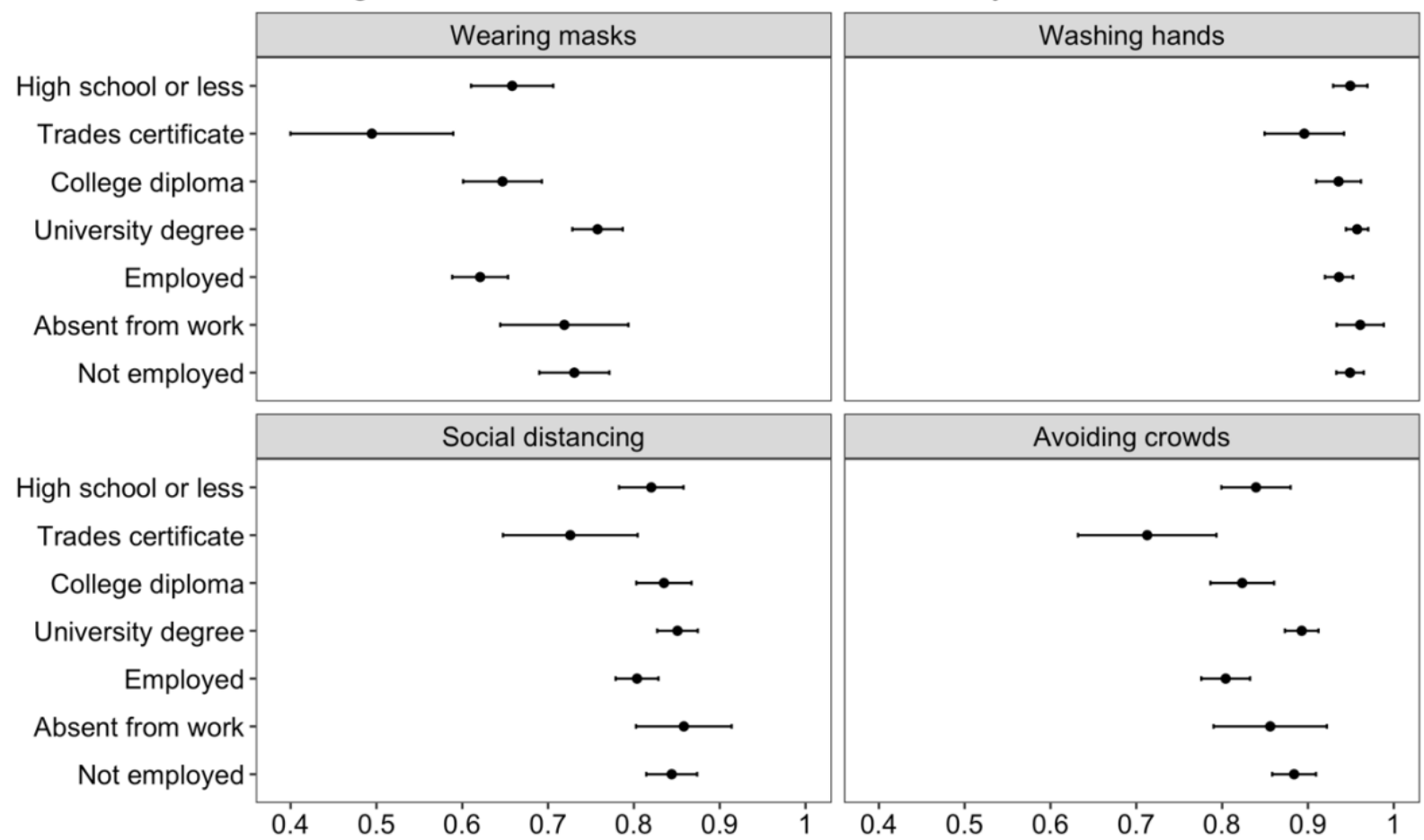




\section{ONLINE SUPPLEMENT}

\begin{tabular}{|c|c|c|c|c|}
\hline & Wearing masks & Hand washing & Social distancing & Avoiding crowds \\
\hline \multicolumn{5}{|l|}{ Demographics } \\
\hline Female & $0.13 * * *$ & $0.05^{* * *}$ & $0.06 * *$ & $0.07 * * *$ \\
\hline \multicolumn{5}{|l|}{ Age } \\
\hline 25 to 44 & -- & -- & -- & -- \\
\hline 45 to 64 & $0.07 *$ & -0.01 & $0.04 *$ & $0.05^{*}$ \\
\hline $65+$ & $0.17^{* * *}$ & 0.02 & $0.06^{*}$ & $0.12 * * *$ \\
\hline Immigrant & $0.19^{* * *}$ & 0.01 & $0.08 * * *$ & $0.10^{* * *}$ \\
\hline Rural & $-0.15 * * *$ & 0.01 & -0.03 & -0.03 \\
\hline \multicolumn{5}{|l|}{ Marital status } \\
\hline Married/Common-law & -- & -- & -- & -- \\
\hline Previously married & -0.01 & -0.01 & 0.01 & -0.03 \\
\hline Single & $-0.12 * *$ & -0.01 & -0.05 & $-0.10^{* *}$ \\
\hline Children present & -0.04 & 0.01 & -0.03 & -0.03 \\
\hline \multicolumn{5}{|l|}{ Socioeconomic status } \\
\hline \multicolumn{5}{|l|}{ Level of Education } \\
\hline High school or less & -- & -- & -- & -- \\
\hline Trades certificate & $-0.16^{* *}$ & $-0.05^{*}$ & $-0.09 *$ & $-0.13 * *$ \\
\hline College diploma & -0.01 & -0.01 & 0.02 & -0.02 \\
\hline University degree & $0.10^{* *}$ & 0.01 & 0.03 & $0.05^{*}$ \\
\hline \multicolumn{5}{|l|}{ Employment status } \\
\hline Employed & -- & -- & -- & -- \\
\hline Absent from work & $0.10^{*}$ & 0.03 & 0.06 & 0.05 \\
\hline Not employed & $0.11^{* * *}$ & 0.01 & $0.04 *$ & $0.08 * * *$ \\
\hline \multicolumn{5}{|l|}{ Dwelling type } \\
\hline Single detached & -- & -- & -- & -- \\
\hline Low-rise apartment & 0.03 & 0.01 & -0.02 & 0.01 \\
\hline High-rise apartment & $0.13 * *$ & -0.00 & $0.09 * *$ & 0.02 \\
\hline Other & 0.02 & 0.01 & 0.00 & 0.01 \\
\hline Observations & 3939 & 3939 & 3939 & 3939 \\
\hline
\end{tabular}

Marginal effects shown

$* \mathrm{p}<0.05 ; * * \mathrm{p}<0.01 ; * * \mathrm{p}<0.001$

All models include sampling weights to account for unequal probability of selection into the sample

Source: Canadian Perspective Survey Series 3 


\begin{tabular}{|c|c|c|c|c|}
\hline & Wearing masks & Hand washing & Social distancing & Avoiding crowds \\
\hline \multicolumn{5}{|l|}{ Demographics } \\
\hline Female & $0.11 * * *$ & $0.05^{* * *}$ & $0.05^{*}$ & $0.06^{* *}$ \\
\hline \multicolumn{5}{|l|}{ Age } \\
\hline 25 to 44 & -- & -- & -- & -- \\
\hline 45 to 64 & $0.06^{*}$ & -0.00 & 0.03 & 0.04 \\
\hline $65+$ & $0.14^{* * *}$ & $0.03 *$ & 0.03 & 0.10 \\
\hline Immigrant & $0.14 * * *$ & 0.00 & $0.06 * *$ & $0.08 * *$ \\
\hline Rural & $-0.10 * *$ & 0.01 & -0.01 & $-0.01 * * *$ \\
\hline \multicolumn{5}{|l|}{ Marital status } \\
\hline Married/Common-law & -- & -- & -- & -- \\
\hline Previously married & -0.06 & -0.02 & -0.01 & -0.07 \\
\hline Single & $-0.07 *$ & 0.00 & -0.03 & -0.06 \\
\hline Children present & -0.02 & 0.01 & -0.03 & -0.02 \\
\hline \multicolumn{5}{|l|}{ Socioeconomic status } \\
\hline \multicolumn{5}{|l|}{ Level of Education } \\
\hline High school or less & -- & -- & -- & -- \\
\hline Trades certificate & -0.08 & -0.03 & -0.06 & -0.07 \\
\hline College diploma & 0.02 & -0.01 & 0.03 & 0.01 \\
\hline University degree & $0.11^{* * *}$ & 0.02 & 0.03 & $0.07 * *$ \\
\hline \multicolumn{5}{|l|}{ Employment status } \\
\hline Employed & -- & -- & -- & -- \\
\hline Absent from work & 0.08 & 0.01 & 0.05 & 0.04 \\
\hline Not employed & $0.06^{*}$ & -0.00 & 0.02 & $0.05 *$ \\
\hline \multicolumn{5}{|l|}{ Dwelling type } \\
\hline Single detached & -- & -- & -- & -- \\
\hline Low-rise apartment & 0.01 & 0.01 & -0.02 & 0.01 \\
\hline High-rise apartment & 0.08 & -0.00 & $0.07 *$ & 0.00 \\
\hline Other & -0.01 & 0.01 & -0.01 & -0.01 \\
\hline Observations & 3939 & 3939 & 3939 & 3939 \\
\hline
\end{tabular}

Marginal effects shown

$* \mathrm{p}<0.05 ; *$ p $<0.01 ; * * \mathrm{p}<0.001$

All models include sampling weights to account for unequal probability of selection into the sample Source: Canadian Perspective Survey Series 3 